\title{
As representaçōes de imagens grafo-táteis para o aluno cego no contexto educativo inclusivo'
}

\author{
Alice Liberto* \\ Célia Ribeiro** \\ Cristina Simóes ${ }^{* * *}$
}

\section{Resumo}

$\mathrm{Na}$ tentativa de se encontrarem algumas respostas para as necessidades decorrentes da nossa prática educativa com alunos cegos, este estudo, de caráter exploratório, teve como principal objetivo conhecer as perceçôes e a importância que os alunos cegos e os professores de educação especial (EE) atribuem às representações de imagens grafo-táteis. Pretendeu, igualmente, perceber a pertinência da sua utilização no contexto educativo atual de inclusão. Com base na observação de seis alunos com cegueira (congénita e adquirida), na identificação de imagens em relevo e no resultado de entrevistas efetuadas a seis professores de EE, foi possível concluir que a representação grafo-tátil é importante e pertinente para o aluno cego no contexto educativo inclusivo. Contudo, há ainda um longo caminho a percorrer na construção e utilização de materiais/imagens em relevo para motivar a aprendizagem e promover um ambiente facilitador da inclusão.

Palavras-chave: Cegueira; Inclusão; Representaçôes grafo-táteis.

* Mestre em Ciências da Educação pela Universidade Católica Portuguesa, Viseu, Portugal.

** Professora Doutora da Universidade Católica Portuguesa, Viseu, Portugal.

*** Doutora em Ciências da Educação da Universidade Católica Portuguesa, Viseu, Portugal. 


\section{The representations of graph-tactile images to the blind student in inclusive educational context}

\section{Abstract}

In an attempt to find some answers to the needs arising from our educational practice with blind students, this exploratory study sought to understand the perceptions and the importance that blind students and special education teachers attach to representations of graph-tactile images. It also aimed to know its readability and identification among blind students and the appropriateness of its use in the present educational inclusion context. This kind of recognition implies a haptic perceptible digitality (tactile and kinaesthetic information), of active tact, essential to the way they prosecute and use figurative information. Based on the observation of six students with blindness (congenital and acquired), on the identification of embossed pictures and on the results of interviews to six special education teachers, it was possible to assume that the graph-tactile representation is important and relevant to the blind student in inclusive educational context. There is however still a long way to go in the construction and use of materials/embossed pictures to motivate the learning and to promote an environment propitious to inclusion.

Keywords: Blindness; Inclusion; Representation of graph-tactile.

\section{Introdução}

Os nossos sentidos modelam o corpo (MONTAGU, 1988), possibilitandonos interagir com a realidade que nos rodeia (DAVIDOFF, 1983; FONSECA, 1984). Todo o conhecimento que se adquire é, em primeiro lugar, uma sensação e, só depois, se transforma em reflexáo, resultando do 'con-tacto' do nosso corpo com o envolvimento.

A perceção visual é determinante na relação que se estabelece com o espaço, com os objetos e com o(s) outro(s). A ausência total da visão, área primária vulnerável (FONSECA, 1999), condiciona e compromete esta relaçáo, bem como o acesso do aluno com cegueira à aprendizagem, ao conhecimento e à cultura, colocando limitaçôes à sua atividade e participação (PEREIRA, 2008a, 2008b).

O défice visual reduz a quantidade de informação que o indivíduo recebe do meio ambiente e, em consequência da gravidade desta alteração, restringe e limita a construçáo do conhecimento sobre o mundo que o rodeia (MARTÍN; BUENO, 1997). Existe um largo espetro de perdas de visão que se baliza entre o conceito de baixa visão (i.e., com acuidades visuais compreendidas entre os $3 / 10$ e 1/10) e a cegueira (OMS-ICD-10, 1999, citada por PEREIRA, 2008b). O conceito de cegueira legal, quase unificado para todos os países ocidentais, abrange uma acuidade visual com correçáo de $1 / 10$ ou quando o campo visual se encontra reduzido a $20^{\circ}$ (LADEIRA; QUEIRÓS, 2002; PEREIRA, 2008b). De acordo com a International Classification of Functioning, Disability, and Health (World Health Organization 
[WHO], 2001), a deficiência visual é uma alteração nas funções sensoriais da visão e estruturas do corpo (olho), que pode comprometer e dificultar a atividade e participação, cujas barreiras ou facilitadores (fatores ambientais) e fatores pessoais podem influenciar positiva ou negativamente o desempenho do aluno e a sua participação nos vários contextos de vida. Segundo a International Statistical Classification of Diseases and Related Health Problems (WHO, 2010), a deficiência visual está classificada em cinco categorias, com duas categorias adicionais (i.e., 0 sem deficiência visual ou deficiência visual ligeira, com a visão igual ou melhor que 3/10; 1 deficiência visual moderada, com a visão entre $3 / 10$ e 1/10; 2 deficiência visual severa, com a visão entre 1/10 e 0,05; 3 cegueira, com a visão entre 0,05 e 0,02; 4 cegueira, com a visão entre 0,02 e perceção luminosa; 5 cegueira, sem perceção luminosa; e 9 para deficiência visual indeterminada ou não classificada). $\mathrm{O}$ termo baixa visão incluído na revisão anterior foi substituído pelas categorias 1 e 2 (i.e., deficiência visual moderada e deficiência visual severa), enquanto as categorias 3, 4 e 5 referem-se à cegueira.

O mundo que nos circunda tende, cada vez mais, a transmitir a informaçáo através de imagens (ALVAREZ; CORTÉS, 2000), o que lança desafios aos profissionais que trabalham com alunos cegos. O presente estudo nasceu da necessidade de se encontrarem respostas às inquietaçôes sentidas na prática pedagógica e pelo vazio existente na literatura. Deste modo, tem como objetivos: (a) conhecer a importância da perceção grafo-tátil de imagens no aluno cego; (b) conhecer a legibilidade de imagens em relevo em alunos cegos; (c) conhecer a importância que os docentes atribuem às representaçóes em relevo e quais os recursos existentes e utilizados habitualmente na sua prática educativa; e (d) reconhecer a pertinência da utilização de representaçôes grafo-táteis no contexto educativo atual de inclusão.

\section{A perceção}

Se a perceção se pode definir "como um processo de organizar e interpretar dados sensoriais recebidos (sensaçôes), para desenvolvermos a consciência do ambiente que nos cerca e de nós mesmos" (DAVIDOFF, 1983, p. 211), esta "subentende a capacidade de extrair significação do envolvimento" (FONSECA, 1984, p. 306). Por conseguinte, a perceção é uma ponte que relaciona o indivíduo com o seu meio envolvente.

A perceção envolve, fundamentalmente, o sujeito e o objeto. Hatwell (1986) considera que só por comodidade de terminologia se fala de "modalidades sensoriais" (p. 23) e não de "modalidades sensoriomotoras" (p. 23). Isto porque todos os sistemas percetivos "têm uma organização muscular própria ou associada que lhes permite deslocar os recetores e explorar o envolvimento" (HATWELL, 1986, p. 23), reforçando que são todos na realidade, percetivo-motores.

Podemos afirmar que os aparelhos sensoriais e motores do corpo humano são interfaces ou um instrumento mediador para a relação com o envolvimento. Os objetos do mundo exterior têm inúmeras propriedades e cada modalidade percetiva dános uma realidade distinta ao serviço da nossa consciência. Esta possibilita, segundo Damásio (2000, p. 44), "ligar o santuário íntimo da regulação da vida à capacidade de manipular imagens". 
Enquanto mediadora intermodal privilegiada, a imagem mental pode constituir um código comum no qual as informaçôes vindas das diferentes fontes podem ser convertidas. Ao dar sentido e significado à informação sensorial, fazendo a ponte entre os componentes físicos e os cognitivos, a perceçáo constitui um processo psiconeurológico fundamental para a aprendizagem e o conhecimento (VIEIRA, 1996).

A capacidade de evocar e de reconhecer, a partir da memória, o tipo de conhecimento que é pertinente para um dado objeto, enquanto esse objeto está a ser percebido, é referido por Damásio (2000) como gnósia. Para Rosa e Ochaita (1993), já náo estamos a falar da maneira como o mundo se constitui através dos mecanismos de acesso à informação, mas de uma negociaçáo dos sentidos, que resulta na sua representaçáo e que é uma criação de significados. Trata-se de uma forma de armazenar conhecimentos que, ao ativar-se para a ação, pode também colaborar e orientar a própria ação. Deste modo, ao construir sistemas funcionais de ação, através do seu desenvolvimento e partindo dos sistemas naturais previamente existentes, cada sujeito vai criar uma história única e singular.

\section{tato e a perceção háptica}

O tato é uma modalidade de contacto e não de perceçáo à distância, tal como é a visão e a audição. Para que seja acionado deve, necessariamente, haver contacto físico entre o estímulo e o recetor sensorial, o que supóe que o campo percetivo disponível e a antecipação percetiva estejam consideravelmente reduzidos. Quando os objetos são grandes, a perceção e o reconhecimento dos mesmos faz-se de forma fragmentada. A recolha de informação é lenta e analítica, enquanto com o uso da visão é rápida e globalizada (VIEIRA, 1996). No entanto, o tato é fundamental para que as pessoas cegas possam recolher informaçóes sobre o seu envolvimento e realizar tarefas diárias, quotidianas e académicas (WITHAGEN et al., 2011a).

O sentido do tato não reside de modo exclusivo nas máos, mas localiza-se de maneira ampla por toda a superfície da pele. Esta é considerada por Damásio (2000) “a maior víscera do corpo" (p. 182). Para Hatwell (1986), a sensibilidade de contacto está estreitamente ligada à funçáo motriz, pois os mecanorreceptores têm a propriedade principal de responderem às mudanças de pressão ou de tração. Logo, ao fazerem parte integrante da estimulação tátil, a deslocação espacial distingue o tato passivo (i.e., ser tocado) quando num segmento corporal imóvel se movimenta, do tato ativo (i.e., perceção tátil-cinestésica ou perceçáo háptica), quando resulta de um movimento ativo e voluntário do sujeito (HATWELL, 1986; MARTÍN; RAMIREZ, 2003).

Hatwell (1986) faz a analogia com a visão, referindo que dada a grande sensibilidade da face interna da mão (a dorsal é bem menos sensível), com uma grande densidade de recetores, os dedos constituem uma espécie de "fóvea tátil" (p. 39), uma superfície recetora que tem um limiar de discriminação bem mais fino e apurado que os outros. Os movimentos manuais põem esta fóvea tátil (ou fóveas) em contacto sucessivo com todas as partes do estímulo. As mãos, órgãos sensoriais da modalidade háptica, têm o poder de interferir nos estímulos proximais e mediais, alterando o seu formato, direção e velocidade, os olhos, órgãos periféricos da visão, não detêm esse poder (AZEVEDO; JOFFILY, 2009). 
Para Leonhardt (2011) e Revuelta (1993), a coordenação visiomotora é substituída na criança cega pela coordenação bimanual e coordenação ouvido-mão. Privado de informação visual, as pessoas cegas congénitas necessitam de mais tempo para estruturar o seu universo auditivo-manual (HATWELL, 1992). Com a autonomia motriz dos segmentos superiores, os movimentos das duas máos podem ser: idênticos, simétricos ou diferentes, podendo ser síncronos ou alternados e levar as duas mãos a explorar regióes separadas do mesmo objeto ou objetos distintos. A assimetria funcional das mãos, própria da espécie humana, aumenta a sua independência motriz, uma vez que cada uma é especializada numa certa função: de suporte ou de ação (HATWELL, 1986).

Para Liébana e Chacón (2004) é importante o papel da perceção háptica ou tato ativo (salientando também, a leitura Braille), na constituição e desenvolvimento da chamada inteligência tátil. Como referem Griffin e Gerber (1996), uma maior compreensão e utilização da modalidade tátil, na aprendizagem das crianças cegas, permitirá perceber como as modalidades se interpenetram para auxiliar o conhecimento do eu na sua relação com o ambiente. Sublinhando-se que o desenvolvimento da perceção tátil é essencial para que as pessoas cegas possam desenvolver a capacidade de organizar, transferir e abstrair conceitos.

\section{A representação grafo-tátil e as imagens táteis}

Para a educaçấo de crianças cegas, no desenvolvimento da modalidade tátil, através de atividades que visem a estimulaçáo apropriada para a aquisição de destrezas, Griffin e Gerber (1996) referem que a ausência da modalidade visual exige experiências alternativas de desenvolvimento de forma a promover a inteligência e as capacidades adaptativas. Neste processo de pleno desenvolvimento da modalidade tátil, os mesmos autores mencionam quatro fases sequenciais, com diferentes níveis de aquisição de capacidades: consciência da qualidade tátil; conceito e reconhecimento da forma (i.e., reconhecimento da estrutura e da relação das partes com o todo); compreensão de representaçôes gráficas; e utilização de simbologia.

Cada uma destas fases tem implicações educativas. Na primeira fase, a consciência das qualidades táteis dos objetos implica que as crianças aprendam a mover as mãos para explorar os objetos, ajudando-a a perceber a sua presença no ambiente e na aquisição de conceitos, inicialmente contrastantes (e.g., mole/duro; macio/áspero; grande/pequeno) e depois, cada vez mais refinados. Na segunda fase, o conceito e o reconhecimento da forma relacionando o todo com as partes, Griffin e Gerber (1996) referem que, em geral, até aos três anos os modelos de representaçáo de todas as crianças não estão separados das açóes sobre os objetos, na semelhança do esquema sensório-motor de Piaget e Inhelder (1979). Depois dos três anos, a criança cega pode comparar o que é lembrado com o que é percebido, num esquema de mediação (GRIFFIN; GERBER, 1996).

As crianças cegas têm o conceito de orientação de uma figura tátil no espaço e encontram um detalhe característico de um objeto que os ajuda a discriminá-lo. Partindo da clareza e simplicidade do desenho e da exploração ativa do objeto, deve ser 
ensinado às crianças cegas formas simples de tamanho pequeno, que possam segurar com as mãos, para mais tarde explorar formas mais complexas em tamanho maior. Quando já conhecem bem as formas de natureza tridimensional, devem ser apresentados objetos bidimensionais (GRIFFIN; GERBER, 1996).

$\mathrm{Na}$ fase seguinte, em interligação com a exploração da forma e partes constituintes dos objetos, surge a representação gráfica. Inicialmente, em relevo, com linhas retas e curvas, formas geométricas e contornos de objetos, até às representaçôes táteis do espaço de locomoção e leitura de mapas. A representação gráfica, enquanto forma organizada de explorar o ambiente, exige a oportunidade de explorar objetos verdadeiros, seguida da comparação das semelhanças entre esses objetos e a sua representação (GRIFFIN; GERBER, 1996). Por fim, a utilização de um sistema de simbologia, sendo o mais comum, o sistema Braille, leva à compreensão de que na utilização de sistemas de simbologia, a sua representação não precisa de ter semelhança com o original mas, simplesmente, significa o objeto (GRIFFIN; GERBER, 1996).

Morice (1992) reforça a urgência da definição de signos figurativos para as pessoas cegas, com a convicção de que o desenho em relevo é fonte de conhecimento. Sublinha a funcionalidade deste código de signos organizados para as pessoas cegas, ao transmitir vários aspetos do objeto, estimular e encorajar a experiência do espaço, responder às exigências da exploração tátil e ao favorecer, também, a leitura das figuras. As pesquisas de Heller, McCthy e Clark (2005) referem que se deve ter em consideração que, nas pessoas cegas, a experiência educacional e a sua capacidade de perceção pode ser muito variável, sugerindo algum cuidado na interpretação dos resultados de qualquer pesquisa com amostras limitadas de participantes. Em estudos de imagem em relevo com cegos, o baixo desempenho pode simplesmente refletir uma relativa inexperiência com as regras que regem a perceção da imagem.

Apesar da falta de familiaridade, os cegos congénitos são capazes de compreender alguns aspetos da perspetiva dos desenhos com linhas em relevo. Desta forma, as imagens em relevo, com superfícies bidimensionais, podem transmitir uma informação útil para os cegos congénitos, embora inicialmente possam surgir algumas dificuldades, estas podem ser superadas com a experiência ou a instrução explícita (BARDISA, 1992; HELLER; MCCTHY; CLARK, 2005).

Para Valente (2008), a facilidade, ou não, de reconhecimento de desenhos depende também, da experiência de vida de cada pessoa cega. Salienta-se que "o desenho precisa de ser realizado de uma forma que se adapte ao contexto percetivo das pessoas cegas" (p. 1014), não se limitando a tornar conteúdos visuais percetíveis aos dedos. Nesta pesquisa, a pessoa cega "desenhando pode conhecer melhor as coisas" (DUARTE, 2008, p. 24).

Na perspetiva de Piekas (2011), "é possível compreender a importância e a necessidade de metodologias direcionadas ao desenho para crianças cegas” (p. 864). De acordo com Duarte (2008), os primeiros registos acidentais e espontâneos que denominam de "entrada na grafosfera" (p. 20), é um indicador do emergir de "um processo cognitivo novo e essencial na vida das crianças" (p. 20). Designam a ação 
realizada e repetida de ícone de gesto e as marcas realizadas de ícone do traço. Duarte (2008) acredita que o ensino do desenho às crianças cegas, através da imitação sensoriomotora (sobreposição das mãos para a realização do traço de desenho, para depois ser repetido por quem imita), pode permitir "a aquisição de um esquema mental do objecto desenhado (e a desenhar) capaz de actuar como recurso cognitivo em que o objecto aprendido pelo desenho possa ser considerado um representante geral de uma categoria de objectos do mundo" (p. 24).

É consensual que, para a pessoa cega, não existe melhor conhecimento do objeto que o objeto real. Na produção de recursos didáticos, considera-se importante a elaboração de um fundo de representações bidimensionais no plano de objetos, símbolos, figuras ou ícones, com a respetiva definiçâo, adaptada ao nível de desenvolvimento da criança (PÉREZ; TOJO, 2009). Sendo o tato um sentido analítico, para que a sua captação seja eficaz, deve realizar-se sobre objetos simples e com uma estrutura predominantemente geométrica (LIÉBANA; CHACÓN, 2004). Para estes autores, "quanto mais simples e esquemático seja o objeto tangível, mais eficaz e completa será a apreensão táctil correspondente” (p. 13). Acrescentam que, por este motivo, as figuras geométricas simples e regulares e as figuras angulares, em especial as quadrangulares, são as mais apropriadas para a captação e apreensão tátil.

Levi e Rolli (1994) propõem um método em que se utilizam as mãos, não para aceder aos símbolos abstratos e codificados (Braille), mas para alcançar signos que são visuais por definição: ícones no pleno sentido do termo. Ou seja, traduzir este mundo de imagens, esta iconosféra em que estamos imersos, numa linguagem diferente destinada a um destinatário que não vê. Examinam os critérios que guiam a simplificação das imagens pictográficas modernas, a fim de a tornar legível. Indicam os critérios de base, para que uma imagem descritiva se torne abstração, equivalente à palavra, apresentando-se como uma experiência adicional em relação aos outros sentidos ou mesmo como uma nova fonte de prazer (ORTOLEVA, 1994).

Para poderem ser interpretadas de forma significativa, as representações táteis em relevo (e.g., mapas, diagramas, ilustrações, imagens) devem ser consideradas nas competências curriculares académicas e serem adaptadas de forma a serem acessíveis aos leitores táteis (MASON; ARTER, 1999). Reforçando-se que "a capacidade de produzir materiais tácteis eficazes e ensinar os alunos como usá-los é uma competência essencial dos professores de crianças e jovens com deficiência visual” (p. 178).

Jalbert e colaboradores (2005) acrescentam que, tal como o Braille, a imagem tátil deverá ser objeto de aprendizagem pela criança cega, pois não faz parte do seu ambiente natural. Por um ângulo de um tocar fragmentário, a criança cega deve aprender a reconhecer uma imagem, fazendo a associaçáo entre esta, o referente e a palavra. Mesmo sendo difícil, a criança cega deve ser colocada em contacto com a imagem em relevo e ser ajudada a fazer a sua aprendizagem desde cedo, pois "a imagem em relevo constitui um útil auxiliar não negligenciável na aprendizagem da leitura" (JALBERT et al., 2005, p. 47). 
O livro tátil-ilustrado é um livro acessível a todos os alunos, para favorecer a inclusão e fomentar uma imagem positiva da DV (CLAUDET, 2012; JALBERT et al., 2005; VALLES; ANDRADE, 2011). Darras e Valente (2010) referem que aos poucos têm vindo a ser corrigidas as falhas de comunicação, tendo vindo a ser refinado o processo de conversão de conteúdos visuais em imagens em relevo. Referem que, apesar de no início do século XXI o campo de aplicação de imagens táteis ser mais amplo, ainda continuam "a desempenhar um papel marginal em todos os dispositivos destinados a promover a acessibilidade à educação e à cultura para os cegos” (p. 2).

Apesar das iniciativas e da escassa investigação, ainda há um longo caminho a percorrer para a compreensão da perceção e representação grafo-tátil nas crianças cegas.

\section{Metodologia}

\section{Caraterização dos participantes}

Em conformidade com os dados expostos na Tabela 1, as idades dos 6 alunos entrevistados situaram-se entre os 10 anos e os 17 anos. Quatro participantes eram do género masculino e 2 do género feminino. Quanto ao ano de escolaridade, 4 frequentavam o $5^{\circ}$ ano (E1, E4, E5 e E6), o E2 o $8^{\circ}$ ano e o E3 o $9^{\circ}$ ano, sendo apoiados ao abrigo do Decreto-Lei n. ${ }^{\circ} 3 / 2008$, de 7 de janeiro, 5 dos quais no âmbito de medidas educativas de adequaçôes curriculares e 1 com currículo específico individual (CEI). No que se refere ao tipo de DV, 3 alunos tinham cegueira adquirida (E1, E4 e E5) e os outros 3 tinham cegueira congénita (E2, E3 e E6).

Tabela 1 - Caracterização dos alunos entrevistados

\begin{tabular}{|c|c|c|c|c|c|}
\hline Entrevistados & Idade & Gênero & $\begin{array}{c}\text { Ano de } \\
\text { Escolaridade }\end{array}$ & Tipo de DV & $\begin{array}{c}\text { Medidas } \\
\text { Educativas }\end{array}$ \\
\hline E1 & 10 & Feminino & $5^{\circ}$ & $\begin{array}{c}\text { Cegueira } \\
\text { adquirida }\end{array}$ & $\begin{array}{c}\text { Adequaçóes } \\
\text { curriculares }\end{array}$ \\
\hline E2 & 17 & Masculino & $8^{\circ}$ & $\begin{array}{c}\text { Cegueira } \\
\text { congênita }\end{array}$ & $\begin{array}{c}\text { Adequaçóes } \\
\text { curriculares }\end{array}$ \\
\hline E3 & 15 & Feminino & $9^{\circ}$ & $\begin{array}{c}\text { Cegueira } \\
\text { congênita }\end{array}$ & $\begin{array}{c}\text { Adequaçóes } \\
\text { curriculares }\end{array}$ \\
\hline E4 & 11 & Masculino & $5^{\circ}$ & $\begin{array}{c}\text { Cegueira } \\
\text { adquirida }\end{array}$ & $\begin{array}{c}\text { Adequaçóes } \\
\text { curriculares }\end{array}$ \\
\hline E5 & 11 & Masculino & $5^{\circ}$ & $\begin{array}{c}\text { Cegueira } \\
\text { adquirida }\end{array}$ & $\begin{array}{c}\text { Adequaçóes } \\
\text { curriculares }\end{array}$ \\
\hline E6 & 13 & Masculino & $5^{\circ}$ & $\begin{array}{c}\text { Cegueira } \\
\text { congênita }\end{array}$ & CEI \\
\hline
\end{tabular}


O grupo dos docentes entrevistados foi constituído por 4 professoras e 2 professores, com idades compreendidas entre os 39 e os 55 anos (cf. Tabela 2). Quanto às habilitaçôes académicas, todos tinham pelo menos o grau de licenciatura e especialização em DV, à exceção da E5. Quanto ao tempo de serviço na educação especial (EE), este vai desde os 9 até aos 21 anos. Salienta-se que a E5 referiu ter 25 anos em EE sem especialização. No que se refere ao tempo de serviço em DV, constatou-se um mínimo de 5 anos e um máximo de 20 anos.

Tabela 2 - Caracterização dos professores entrevistados

\begin{tabular}{|c|c|l|c|c|c|c|}
\hline Entrevistados & Idade & Gênero & $\begin{array}{c}\text { Habilitaçóes } \\
\text { Acadêmicas }\end{array}$ & $\begin{array}{c}\text { Área de } \\
\text { Especializaçáo }\end{array}$ & $\begin{array}{c}\text { Tempo de } \\
\text { Serviço na EE }\end{array}$ & $\begin{array}{c}\text { Tempo de } \\
\text { Serviço com } \\
\text { Alunos com DV }\end{array}$ \\
\hline E1 & 50 & Feminino & $\begin{array}{c}\text { DESE em } \\
\text { EE }\end{array}$ & DV & 24 & 9 \\
\hline E2 & 55 & Feminino & Licenciatura & DV & 15 & 5 \\
\hline E3 & 40 & Feminino & Licenciatura & DV & 7 & 7 \\
\hline E4 & 54 & Masculino & $\begin{array}{c}\text { Licenciatura } \\
\text { DESE em } \\
\text { EE Mestrado }\end{array}$ & $\begin{array}{c}\text { DV } \\
\text { Problemas } \\
\text { intelectuais/ } \\
\text { motores }\end{array}$ & 21 & 20 \\
\hline E5 & 54 & Feminino & Licenciatura & $\begin{array}{c}\text { Sem } \\
\text { Especializaçáo }\end{array}$ & 25 & 8 \\
\hline E6 & 39 & Masculino & Mestrado & DV & 9 & 9 \\
\hline
\end{tabular}

\section{Instrumentos}

Para a realizaçáo deste estudo foram utilizados como instrumentos de recolha de dados: uma grelha para observar o desempenho dos alunos na identificação de imagens em relevo, bem como uma entrevista semiestruturada.

A grelha de observação é constituída por sete parâmetros, nomeadamente: número de imagens (de 0 a 10); nome das imagens em relevo; identificação (sim/ não); tempo; tentativas; observaçóes e escolhas. As imagens representavam uma árvore (para treino experimental); uma maçá; uma chávena; uma tesoura; um telefone (adotamos um telemóvel, atualmente mais comum e familiar); uma chave; uma cara contente; uma garrafa e uma mesa. Salienta-se que adicionamos, ao conjunto destas imagens mais um objeto de uso comum, uma colher de sopa e quatro figuras geométricas: o círculo (denominação que adotamos para a circunferência, por ser um termo mais familiar); quadrado; retângulo e triângulo, representaçóes familiares e comuns no contexto educativo dos alunos.

A entrevista elaborada para este estudo foi a semiestruturada, pois foram definidas algumas questóes que funcionaram como um guiấo da mesma. Em função dos objetivos definidos foram assim, construídos dois guióes de entrevista, um dedicado aos professores e outro aos alunos. 


\section{Procedimentos}

No presente estudo, desenvolveu-se uma abordagem e pesquisa qualitativa, procurando "compreender as perceçôes individuais" (BELL, 2008, p. 19), com recolha de dados essencialmente descritiva. Efetuou-se uma adaptação das imagens em relevo usadas por D’Angiulli (2007).

Inicialmente, era dada a imagem da árvore ao aluno para ele poder explorar. Posteriormente, era dada uma imagem de cada vez para que tentasse identificá-la, dizendo o nome do objeto representado. Após este momento, era referido o que cada imagem pretendia representar, sendo solicitada alguma introspeção subjetiva sobre as mesmas, através de uma entrevista semiestruturada ao aluno. No final, o aluno era convidado a fazer um desenho livre em papel com lápis de cera, no suporte rugoso da prancha do estojo de desenho.

Para complementar os dados obtidos com os alunos, contactámos docentes de EE de alunos com cegueira, que foram convidados a refletir, através de uma entrevista semiestruturada, sobre esta temática na sua prática educativa.

\section{Resultados}

De acordo com a aplicação do teste das imagens em relevo (cf. Tabela 3), observámos que as figuras geométricas foram identificadas por todos os alunos, o mesmo náo se tendo sido verificado nas restantes imagens utilizadas na presente investigação.

Tabela 3 - Resultados globais do teste das imagens em relevo

\begin{tabular}{|c|c|c|c|c|c|c|}
\hline \multirow{2}{*}{$\begin{array}{c}\text { Imagens em } \\
\text { Relevo }\end{array}$} & \multicolumn{2}{|c|}{ Identificação } & \multicolumn{2}{|c|}{ Escolha } & \multicolumn{2}{|c|}{ Totais } \\
\hline & $\mathrm{CC}$ & CA & $\mathrm{CC}$ & $\mathrm{CA}$ & $\mathrm{CC}$ & CA \\
\hline Árvore & 0 & 0 & 0 & 0 & 0 & 0 \\
\hline $\begin{array}{c}\text { Figuras } \\
\text { Geométricas }\end{array}$ & E6-E3-E2 & E1-E4-E5 & - & - & 3 & 3 \\
\hline Maçã & E3-E2 & E1-E4 & $\mathrm{E} 2$ & $\mathrm{E} 5^{* *}$ & 2 & 2 \\
\hline Chávena & E3 & E1 & - & - & 1 & 1 \\
\hline Tesoura & E3* & E1 & E6 & - & 1 & 1 \\
\hline Telemóvel & E3* & E1-E4-E5 & - & E4 & 1 & 3 \\
\hline Chave & - & $\mathrm{E} 1^{*}$ & - & - & - & 1 \\
\hline $\begin{array}{c}\text { Cara } \\
\text { Contente }\end{array}$ & $\mathrm{E} 3^{*}$ & E1-E4-E5 & - & - & 1 & 3 \\
\hline Garrafa & - & E1-E4-E5 & - & - & - & 3 \\
\hline Mesa & - & E1-E5 & - & E1 & - & 2 \\
\hline $\begin{array}{l}\text { Colher de } \\
\text { Sopa }\end{array}$ & - & E1-E5 & E3 & - & 0 & 2 \\
\hline
\end{tabular}

$\left.{ }^{*}\right)$ Demorou mais tempo na identificação e precisou de pistas verbais; $\left.{ }^{* *}\right)$ Foi considerada a imagem mais fácil de reconhecer pelo aluno, na sua opinião, mas referiu gostar de todas; CC: Cegueira Congénita; CA: Cegueira Adquirida. 
Tal como se pode observar na Tabela 4, constatou-se, através da análise das unidades de registo dos alunos entrevistados, que, na generalidade, os mesmos reconhecem que as imagens de relevo ajudam a perceber os objetos (E1 e E3), a perceber os mapas (E4 e E5) e que ajudam a perceber melhor alguns objetos e os conteúdos abordados nas aulas (E6). Apenas o E2 considera que deveria haver mais orientação com legendas, pois tem muita dificuldade em identificar os objetos representados, sobretudo compreender os mapas. Refere-se que o E3 acrescentou que este tipo de imagens "Estavam bem" e que "Já devia ter trabalhado mais com este tipo de objetos e materiais". O E4 mencionou que "Gostava de ver nos livros estas imagens" e o E5 considerou que "Estavam bem as imagens".

Tabela 4 - A importância das imagens em relevo para os conteúdos abordados nas aulas (perceção dos alunos)

\begin{tabular}{|c|c|c|c|}
\hline Categoria & Subcategoria & $\begin{array}{l}\text { Unidades de } \\
\text { Registro }\end{array}$ & $\begin{array}{l}\text { Número de } \\
\text { Ocorrências }\end{array}$ \\
\hline \multirow{4}{*}{$\begin{array}{l}\text { Ajuda das imagens } \\
\text { em relevo para } \\
\text { perceber melhor } \\
\text { alguns objetos e os } \\
\text { conteúdos aborda- } \\
\text { dos nas aulas }\end{array}$} & $\begin{array}{c}\text { Ajudam a perceber } \\
\text { os objetos }\end{array}$ & $\begin{array}{l}\text { E1 "Sim, ajuda a } \\
\text { perceber os objetos". } \\
\text { E3 "Sim, dá-me } \\
\text { ideia como são os } \\
\text { objetos na realidade". }\end{array}$ & 2 \\
\hline & $\begin{array}{c}\text { Ajudam a perceber } \\
\text { os mapas }\end{array}$ & $\begin{array}{l}\text { E4 "Sim. Os mapas } \\
\text { gosto mais ou menos } \\
\text { de ver, não se perce- } \\
\text { bem muito bem". } \\
\text { E5 "Sim ajuda. Gos- } \\
\text { to de ver mapas sim- } \\
\text { ples. O mapa-múndi } \\
\text { com mais informa- } \\
\text { çáo e muito porme- } \\
\text { norizada é mais com- } \\
\text { plicado. Ao longo da } \\
\text { escolaridade e ima- } \\
\text { gem mais usada é o } \\
\text { mapa de Portugal". }\end{array}$ & 2 \\
\hline & Não ajudam muito & $\begin{array}{c}\text { E2 "Devia haver } \\
\text { mais orientação, } \\
\text { com legendas. Te- } \\
\text { nho muita dificulda- } \\
\text { de... os mapas sáo } \\
\text { confusos". }\end{array}$ & 1 \\
\hline & $\begin{array}{c}\text { Ajudam a perceber } \\
\text { os objetos e os } \\
\text { conteúdos }\end{array}$ & E6 "Sim”. & 1 \\
\hline
\end{tabular}


A Tabela 5 revela que todos os professores inquiridos consideram que a representaçáo de imagens em relevo promove o desenvolvimento dos conteúdos programáticos.

Tabela 5 - A importância das imagens em relevo para os conteúdos abordados nas aulas (perceçâo dos professores)

\begin{tabular}{|c|c|c|c|}
\hline Categoria & Subcategoria & $\begin{array}{l}\text { Unidades de } \\
\text { Registo }\end{array}$ & $\begin{array}{l}\text { Número de } \\
\text { ocorrências }\end{array}$ \\
\hline $\begin{array}{l}\text { A representação de } \\
\text { imagens em relevo } \\
\text { para o desenvolvi- } \\
\text { mento dos conteú- } \\
\text { dos programáticos }\end{array}$ & Promove & $\begin{array}{l}\text { E1 "Creio que sim, } \\
\text { na medida em que } \\
\text { ilustra a informação } \\
\text { que está a ser apre- } \\
\text { sentada ou trabalha- } \\
\text { da”. } \\
\text { E2 "Acho que } \\
\text { sim...". } \\
\text { E3 "Sim, serve de } \\
\text { complemento à con- } \\
\text { solidação dos conte- } \\
\text { údos, principalmen- } \\
\text { te aqueles que são } \\
\text { mais abstratos". } \\
\text { E4 "Ajuda os alunos } \\
\text { a terem uma noção } \\
\text { ainda que aproxi- } \\
\text { mada daquilo que } \\
\text { os outros também } \\
\text { estáo a observar e a } \\
\text { realizar". } \\
\text { E5 "Com toda a cer- } \\
\text { teza. Pensemos nas } \\
\text { figuras geométricas: } \\
\text { como pode o aluno } \\
\text { conhecê-las sem a } \\
\text { sua representação } \\
\text { em relevo?". } \\
\text { E6 "Sim...". }\end{array}$ & 6 \\
\hline
\end{tabular}




\section{Discussão}

Analisando, resumidamente, os dados obtidos, verificámos que tanto os alunos como os professores, na sua maioria, reconhecem e atribuem importância e pertinência às representaçôes grafo-táteis nos alunos cegos.

Relativamente aos resultados do teste de identificação das imagens em relevo, verificámos que apenas as figuras geométricas foram identificadas por todos os alunos (inclusive o aluno com CEI). Nas restantes imagens há um número muito limitado de identificaçôes, sendo maior o número de imagens identificadas pelos alunos com cegueira adquirida (por referências às imagens visuais anteriores à cegueira, facilitadores da perceção global da forma) e nas alunas do sexo feminino. Estes resultados são diferentes dos observados no estudo de D’Angiulli (2007), dado que na resposta identificativa das imagens o aluno com cegueira congénita inicialmente identificou $62 \%$ das imagens e posteriormente, todas as imagens, exceto a maçã.

As reflexóes intersubjetivas dos alunos através da entrevista semiestruturada revelaram que todos os alunos, com exceção do aluno mais velho, gostam de imagens em relevo e de desenhar. Com exceção do aluno mais velho, que refere que as imagens não ajudam (sugerindo mais orientação e legendas, pois tem muita dificuldade em identificar os objetos representados e advoga que os mapas são confusos), os restantes alunos reconhecem que as imagens ajudam a perceber objetos e os conteúdos abordados nas aulas, mas referem a necessidade de trabalhar mais com este tipo de materiais e sugerem outras formas de representação mais simplificada de algumas imagens, idênticas às sugeridas pelo aluno no estudo de D'Angiulli (2007).

De salientar, pelo resultado do teste e pelas sugestóes e comentários, que, na sua maioria, as imagens com uma representação mais simplificada (maçãa, colher e figuras geométrica) e as imagens com as quais estão mais familiarizados (as figuras geométricas) são as mais facilmente identificadas pelos alunos cegos.

Esta constatação pode sugerir várias interpretaçôes. Por um lado, a identificação por todos os alunos das figuras geométricas pode resultar de uma familiaridade, experiência e contacto com a sua representação, contrariamente aos outros objetos. Nesta perspetiva, a experiência prévia, a aprendizagem e treino precoce são fatores importantes para o reconhecimento e identificação das mesmas, em especial para alunos cegos congénitos. Estes fatores também foram elencados por outros autores (BARDISA, 1992; DIAS, 1995; GONZÁLEZ; BOUDET, 1995; GRIFFIN; GERBER, 1996; HELLER; MCCTHY; CLARK, 2005; WITHAGEN et al., 2011b).

As dificuldades referidas, de acordo com Heller, McCthy e Clark (2005), podem indicar também, dificuldades em encontrar a palavra para nomear, uma vez que na interpretação háptica de imagens bidimensionais sem nomeação o desempenho melhora significativamente. Assim, como reforçam Alvarez e Cortés (2000) e Pérez e Tojo, (2009), o aluno cego deve habituar-se a explorar no plano bidimensional uma realidade objetal e iconográfica. No entanto, referem que estas diferenças entre o símbolo e o objeto devem ser explicadas ao aluno para que possa compreendê-las, para que ao tornarem-se inteligíveis as possa integrar nos seus esquemas cognitivos. 
A transposição grafo-tátil das imagens pode não ser a mais adequada e a sua representação estar mais de acordo com uma perspetiva ótica e visual, limitando-se, como refere Valente (2008), a tornar conteúdos visuais percetíveis aos dedos e não respeitar as exigências de simplificação da perceção tátil e háptica. Este aspeto foi referido nas sugestões dos alunos da presente investigação e defendido por outros autores (CZIKER, 2012; DARRAS; VALENTE, 2010; HATWELL, 1986; JALBERT et al., 2005; JIMÉNEZ, 1999; LEVI; ROLLI, 1994; ORTOLEVA, 1994; PÉREZ; TOJO, 2009; VALENTE, 2008). Os materiais adaptados, em particular as ilustraçóes com conteúdos visuais e táteis são essenciais também, para os alunos com cegueira adquirida enquanto treino precoce do tato, tal como defende Alvarez e Cortés (2000).

Nesta perspetiva, é de salientar as particularidades de funcionamento da perceção háptica relativamente à visão, referidas por Bardisa (1992) e Liébana e Chacón (2004), em que se destaca uma exaustiva perceçâo dos detalhes em detrimento da apreensão da forma total; a sua natureza primordialmente cognitiva e intencional por oposição à natureza espontânea, recetiva e passiva da perceção visual. Assim, como refere Hatwell (1986), para compensar a exiguidade do campo percetivo, os movimentos desencadeados pelo sujeito são necessários para aprender a totalidade do objeto.

Relativamente aos resultados obtidos nas entrevistas semiestruturadas aos professores, todos referiram o uso de imagens em relevo com os seus alunos, na sua maioria elaboradas pelos próprios professores, com diversos materiais, ou facultadas pelos Centros de Recursos, através dos manuais. Todos referiram que a representação de imagens em relevo ajuda os alunos a percecionar objetos e promove o desenvolvimento dos conteúdos programáticos, manifestando também serem de grande importância e, na opinião de um dos professores, imprescindíveis para os alunos cegos.

Em síntese, a opinião dos professores, para além de reforçar e sublinhar o que é referido pelos alunos, quanto à sua perceção das imagens e reconhecida importância desta ferramenta, acrescenta a necessidade de explicação e acompanhamento docente na leitura das mesmas.

Apesar do que se preconiza na legislação atual sobre a inclusão e a concentração de recursos para que se possa oferecer uma resposta educativa de qualidade a estes alunos, muito há ainda a fazer e a implementar nas várias vertentes da EE, nomeadamente para os alunos com patologia visual de cegueira e baixa visão.

\section{Conclusão}

O estudo implementado, apesar de ter ajudado a vislumbrar a pertinência desta temática para o aluno cego no contexto educativo inclusivo atual, não é um estudo completo, mas antes uma primeira abordagem, um ensaio e um ponto de partida. A necessidade de aperfeiçoamento da metodologia ficou bem patenteada na frustração revelada por muitos alunos perante a incapacidade de leitura de várias imagens, o que os expunha a um constrangimento a evitar em futuras abordagens. Isto acontecia, na nossa opiniáo, por falta de experiência, treino e aprendizagem dos alunos e por insuficiências técnicas das imagens, que não respeitavam as orientaçóes mais atuais da comunidade científica, que nos eram desconhecidas inicialmente. 
Os resultados dos alunos e dos professores apontam para a grande importância, pertinência e atualidade desta temática na intervenção educativa de crianças com DV no atual contexto educativo de inclusão. Enfatiza-se a importância curricular desta temática no desenvolvimento da criança cega, desde o Jardim de Infância. Desde a descoberta revolucionária do Braille até aos produtos recentes das novas tecnologias, os progressos têm sido incessantes. Há, no entanto, muito ainda a fazer. Por exemplo, o desenho considerado como um meio específico de comunicaçáo mesmo para quem não vê, é sem dúvida uma área de pesquisa e experimentação a explorar (ORTOLEVA, 1994).

Levi e Rolli (1994) sugerem alguns critérios base para que a imagem descritiva se torne abstração equivalente à palavra. Ou seja, regras de transformação da imagem em símbolo. De entre as diferentes consideraçôes, sobre as adaptaçóes em relevo, para que os cegos acedam ao mundo das imagens, salientam que os signos gráficos e ícones utilizados devem ter uma configuração essencial, clara e facilmente percetível ao tato de forma a serem imediatamente e automaticamente reconhecidos, realçando que a exploração da imagem, interpretação e principalmente a leitura final, exige aprendizagem, algum tempo e a ajuda de um suporte verbal adequado. Nesta perspetiva, Mason e Arter (1999) referem que pesquisas recentes, nesta área sublinham a importância do desenvolvimento, em idades precoces, de competências táteis que, por sua vez, são influenciadas pelo desenvolvimento da memória de curto-prazo, capacidades espaciais, habilidades motoras finas, técnicas de procura e digitalizaçấo.

Para poderem ser interpretadas de forma significativa, as representações táteis em relevo (mapas, diagramas, ilustraçôes, imagens, entre outras) devem ser consideradas nas competências curriculares académicas e serem adaptadas de forma a poderem estar acessíveis aos leitores táteis (MASON; ARTER, 1999). Os mesmos autores reforçam que "a capacidade de produzir materiais tácteis eficazes e ensinar os alunos como usá-los é uma competência essencial dos professores de crianças e jovens com deficiência visual" (p. 178). Observa-se que, para os autores que estudaram esta temática é consensual a necessidade de haver imagens táteis nos livros concebidos para crianças cegas (JALBERT et al., 2005). Para Lewi-Dumont (1997) citado por Jalbert e colaboradores (2005), "o livro táctil desempenha um papel importante na integração social dos cegos” (p. 46). Valles e Andrade (2011) desenvolveram um trabalho, num grupo de crianças com 4 anos onde se encontrava uma criança com deficiência visual grave, através da adaptação de contos, para motivar a aprendizagem da leitura e escrita (a negro e em Braille, com ilustraçóes em relevo) e para promover um ambiente favorável à inclusão num meio que não está alfabetizado e, portanto, em que "há uma redução quase total de aprendizagem espontânea" (p. 3). As autoras referem que esta experiência foi muito positiva para todos os implicados (i.e., alunos, famílias e professores), salientando que facilitou a inclusão da aluna cega e que os livros com ilustraçôes táteis serviram também para trabalhar

a perceção táctil, a gema dos dedos, as habilidades motrizes necessárias para o movimento ordenado que requer a leitura dos signos Braille, assim como reforçar os conceitos espaciais, temporais e numéricos. Para além como é óbvio, a linguagem e as competências sociais (p. 11). 
Seria importante que, futuramente, os alunos pudessem ter acesso a contos adaptados (em Braille e com imagens táteis), de forma a enriquecer a prática educativa e fomentar a escola inclusiva. Dos livros observados, os editores Les Doigts Qui Rêvent (LDQR) embora estejam a fazer um esforço constante para levar em consideração o contexto percetivo dos cegos, ainda revelam problemas por resolver, de forma a criar uma interface gráfica entre as pessoas cegas e o mundo visual (DARRAS; VALENTE, 2010). Considerando ainda os aspetos a aperfeiçoar, foi gratificante verificar que a perceção grafo-tátil de imagem no aluno cego é uma temática bem aceite e com grande recetividade, quer para os alunos, quer para os professores.

\section{Bibliografia}

ALVAREZ, M.; CORTÉS, E. Aprender a ver, aprender a tocar. Integración, n. 33, p. 20-25, 2000.

AZEVEDO, P.; JOFFILY, S. Arranjos cognitivos: Abrangências e limitaçôes representacionais. Psicologia: Teoria e Pesquisa, n. 25, p. 595-601, 2009.

BARDISA, L. Como ensenar a los niños ciegos a dibujar. Madrid: ONCE, 1992.

BELL, J. Como realizar um projeto de investigação: Trajetos. Lisboa: Gradiva, 2008.

CLAUDET, P. Les Doigts Qui Rêvent (LDQR). Dijon, France: Éditions LDQR, 2012. Disponível em: <http//:www.ldqr.org $>$. Acesso em: 18 ago. 2012.

CZIKER, R. The exploration of tactile images: Pre-Braille guide for young blind children, 2012. Disponível em: <http//:www.rcziker@yahoo.com>. Acesso em: 10 ago. 2012.

D'ANGIULLI, A. Raised-line pictures, blindness, and tactile "beliefs": An observacional case study. JVIB, n. 3, p. 172-177, 2007.

DAMÁSIO, A. O sentimento de si: o corpo, a emoçấo e a neurobiologia da consciência. Mira-Sintra: Publicaçōes Europa América, 2000.

DARRAS, B.; VALENTE, D. Tactile images: Semiotic reflections on tactile images for the blind. The haptic International Journal, n. 1, p. 1-16, 2010.

DAVIDOFF, L. Introduçáo à psicologia. São Paulo: Editora McGraw-Hill, 1983.

DIAS, M. Ver, náo ver e conviver. Lisboa: Editor Secretariado Nacional de Reabilitação, 1995.

DUARTE, M. A imitação sensório-motora como uma possibilidade de aprendizagem do desenho por crianças cegas. Ciências \& Cogniçáo, n.13, p.14 - 26, 2008.

FONSECA, V. Uma introdução às dificuldades de aprendizagem. Lisboa: Edições 70, 1984.

FONSECA, V. (1999). Perturbaçóes do desenvolvimento e da aprendizagem: Tendências filogenéticas e ontogenéticas. Lisboa: Ediçóes FMH, 1999.

GONZÁLEZ, A.; BOUDET, A. Importancia de las representaciones gráficas táctiles en las estratégias didácticas para el aprendizaje de los conceptos espaciales. Integración, n.18, p.43 - 47, 1995.

GRIFFIN, H.; GERBER, P. (1996). Desenvolvimento tátil e suas implicaçốes na educação de crianças cegas. Revista Benjamin Constant, n.5, 1996. Disponível em: <http//:www.ibc.gov.br>. Acesso em: 27 jul. 2012.

HATWELL, Y. Toucher l'espace, la main et la perception tactile de l'espace. Paris: Presses Universitaires de Lille, 1986.

HATWELL, Y. Le développement des perceptions tactiles et les coordinations visuo-tactiles: implication pour l'éducation des déficients visuels. Le Courrier de Suresnes, n.56, p.53 - 60, 1992.

HELLER, M., MCCTHY, A.; CLARK, A. Pattern perception and pictures for the blind. Psicológica, n. 26, p. $161-171,2005$.

JALBERT, Y., et al. Le développement de la conscience de l'écrit, chez l'enfant avegeule âgé de $\mathbf{0}$ a 5 ans: Recension des écrits. Québec: Éditeur Institut Nazareth et Louis-Braille, 2005.

JIMÉNEZ, S. Evaluación de las habilidades hápticas. Integración, n.31, p.5 - 13, 1999. 
LADEIRA, F.; QUEIRÓS, S. Compreender a baixa visão. Lisboa: Ministério da Educaçấo-Departamento de Educação Básica, 2002.

LEONHARDT, M. Vínculo e etapas do desenvolvimento emocional da criança com cegueira: Sinais de comunicação, pontos fortes e fragilidades. II Jornadas Deficiência Visual \& Intervenção Precoce. Coimbra: CAIPDV-ANIP, 2011.

LEVI, F.; ROLLI, R. Disegnare per le mani: Manuale di disegno in rilievo. Torino: Sílvio Zamorani Editore, 1994.

LIÉBANA, I.; CHACÓN, D. Guía didáctica para la lectoescritura Braille. Madrid: ONCE, 2004.

MASON, H.; ARTER, C. The preparation of raised diagrams. In: H. MASON, C. et al. STONE (Eds.). Visual impairment: Access to education for children and young people (p. $171-178)$. London: David Fulton Publisher, 1999.

MARTÍN, M.; BUENO, S. Deficiente visual e acção educativa. In: R. Bautista (Ed.). Necessidades educativas especiais (p. 317 - 347). Lisboa: Dinalivro, 1997.

MARTÍN, M.; RAMIREZ, S. Visão subnormal. In: M. Martín; S. Bueno (Eds.). Deficiência visual: Aspectos psicoevolutivos e educativos (p. 27 - 44). São Paulo: Livraria Santos Editora, 2003.

MONTAGU, A. Tocar o significado humano da pele. São Paulo: Summus Editorial, 1998.

MORICE, J. Des représentations en relief : De la projection orthogonale appliquée aux représentations en relief. Le Courrier de Suresnes, n.56, p.83 - 88, 1992.

ORTOLEVA, P. Toucher pour regarder. In: F. LEVI; R. ROLLI (Eds.). Disegnare per le mani: Manuale di disegno in rilievo (pp. 132 - 133). Torino: Sílvio Zamorani Editore, 1994.

PEREIRA, F. Educaçáo especial: Manual de apoio à prática. Lisboa: DGIDC, 2008a

PEREIRA, F. Alunos cegos e com baixa visão: Orientaçôes curriculares. Lisboa: DGIDC, 2008b.

PÉREZ, J.; TOJO, J. O libro das palabras. Galícia: Centro de Recursos Educativos, ONCE, 2009.

PIAGET, J.; INHELDER, B. A psicologia da criança: Do nascimento à adolescência. Lisboa: Moraes Editora, 1979.

PIEKAS, M. O desenho infantil e os objetos do mundo: construindo um método de ensino no âmbito da invisualidade (Dissertação de Mestrado não publicada). UDESC: Santa Catarina. Brasil, 2011. Disponível em: <http://www.anpap.org.br>. Acesso em: 18 ago. 2012.

REVUELTA, R. Palmo a palmo. Madrid: ONCE, 1993.

ROSA, A.; OCHAITA, E. Introducción. In: A. Rosa; E. Ochaita (Eds.). Psicología de la ceguera (p. 1 - 18). Madrid: Alianza Editorial, 1993.

VALENTE, D. Imagens que comunicam aos dedos: A fabricaçấo de desenhos táteis para pessoas cegas. 17o Encontro Nacional da Associação Nacional de Pesquisadores em Artes Plásticas: Panorama da Pesquisa em Artes Visuais. Florianópolis, ANPAP, 2008.

VALLES, P.; ANDRADE, P. Cuentos para aprender y disfrutar con los amigos. Integragración, n. 59, p.1 14. Madrid: ONCE, 2011.

VIEIRA, M. Plasticidade cerebral no déficit visual. Arquivos Portugueses de Oftalmologia, n. 2, p.5 - 46, 1996.

WITHAGEN, A., et al. Funcionamiento táctil en niños que son ciegos: Una perspectiva clínica. Integración, 60, 1 - 15, 2011a.

WITHAGEN, A., et al. El Tactual Profile: Desarrollo de un instrumento para evaluar el funcionamiento táctil de los nińos ciegos. Integración, n. 59, p.1 - 15, 2011 b.

World Health Organization. International Classification of Functioning, Disability, and Health (ICF). Geneva, Switzerland: World Health Organization, 2001.

World Health Organization. International Statistical Classification of Diseases and Related Health Problems (ICD-10; 10th Revision). Geneva, Switzerland: World Health Organization, 2010. 
Alice Liberto - Célia Ribeiro - Cristina Simões

\section{Notas}

${ }^{1}$ Este artigo é, parcialmente, parte integrante da Dissertação de Mestrado em Ciências da Educação, Especialização em Educação Especial, apresentada no Centro Regional de Viseu da Universidade Católica Portuguesa, em 2013.

\section{Correspondência}

Célia Ribeiro - Centro Regional de Viseu, Universidade Católica Portuguesa. Estrada da Circunvalação - CEP: 3504-505, Viseu, Portugal.

E-mail: aliber@sapo.pt - cribeiro@viseu.ucp.pt - cristina-ferreira@iol.pt

Recebido em 22 de abril de 2016

Aprovado em 22 de dezembro de 2016 